\title{
Quantitative and Qualitative Estimation of Urinary Kallikrein in a Patient with Bartter's Syndrome
}

\author{
Kenichi YAMADA ${ }^{1}$, Mikio WATANABE ${ }^{1}$, Tetsuo NiSHIKAWA ${ }^{1}$, \\ KEIJI MIKAMI ${ }^{1}$, KoJI SHIRAI ${ }^{1}$, YASUSHI TAMURA ${ }^{1}$, \\ MASAHIRo YAMAMOTO ${ }^{1}$, AKIRA KUMAGAI ${ }^{1}$, \\ Yoshifumi MATSUDA ${ }^{2}$ AND HIROSHI MORIYA ${ }^{2}$ \\ ${ }^{1}$ The 2nd Department of Internal Medicine, Chiba University School \\ of Medicine, Inohana 1-8-1, Chiba 280, Japan and ${ }^{2}$ Laboratory \\ of Physiological Chemistry, Faculty of Pharmaceutical Sciences, \\ Science University of Tokyo, Shinjuku, Tokyo 162, Japan
}

\begin{abstract}
Synopsis
Urinary kallikrein in a patient with Bartter's syndrome was remarkably higher than normal. Indomethacin treatments increased serum potassium concentration and urinary $\mathrm{Na} / \mathrm{K}$ ratio, and improved the response of blood pressure to angiotensin II infusion, while it decreased plasma renin activity, plasma aldosterone and urinary kallikrein.

The purified urinary kallikrein had one component of the iso-electric point 4.3 by isoelectric focusing using Ampholine system, and its molecular weight was $4.2 \times 10^{4}$, which was greater than those of three components of normal human urinary kallikreins (normal HUK). Also Km values with TAME and BAME of urinary kallikrein in our patient with Bartter's syndrome did not correspond to those of normal HUK. Thus it can be said that urinary kallikrein in our patient with Bartter's syndrome was qualitatively different from normal HUK. The present observation might be a reflection of renal tubular dysfunction in this patient with Bartter's syndrome.
\end{abstract}

Bartter's syndrome is characterized by hyperreninemia, excessive aldosterone production, hypokalemia, metabolic alkalosis, J.G. cell hyperplasia, vascular-insensitivity to angiotensin II and an abnormality in the renal tubular reabsorption of sodium (Solomon and Brown, 1975; Tomko et al.,

\section{Received April 13, 1978.}

The following abbreviations and trivial names are used:

AcAME; $\mathrm{N}$ - $\alpha$-acetyl-L-arginine methyl ester, AGLME; acetyl-glycyl-L-lysine methyl ester, AME; L-arginine methyl ester, BAME; N- $\alpha$-benzoyl-Larginine methyl ester, LME; L-lysine methyl ester, PAME; L-phenylalanyl-L-arginine methyl ester, TAME; N- $\alpha$-tosyl-L-arginine methyl ester, TLME; $\mathrm{N}$ - $\alpha$-tosyl-L-lysine methyl ester, ZAME; $\mathrm{N}$ - $\alpha$-carbobenzoxy-L-arginine methyl ester.

This work was supported by grants from the Ministry of Education, Science and Culture (248187 \& 257542), Japan.
1976). Recent studies demonstrated the excessive production of prostaglandin aud kallikrein in Bartter's syndrome, both of which are vasodepressive and natriuretic substances and could be closely related to the underlying pathogenesis of this syndrome (Gill et al., 1976a; McGiff, 1977). Here we have investigated the character of urinary kallikrein in one patient with Bartter's syndrome and found its properties were somewhat different from those of normal subjects.

\section{Case Report}

A 48-year-old woman was admitted to hospital with a history of progressive muscular weakness, polydypsia and polyuria. 
About 2 months prior to admission, she developed progressive fatigability, muscular weakness and occasional attacks of nausea and vomiting. A marked hypokalemia was found and the patient was referred to our hospital for the evalutation of hypokalemia. Ten years ago, hypokalemia was noted and she received potassium supplements for a short period. Since then polydypsia and polyuria have been noted. She denied any medication inducing hypokalemia. Her family history was non-contributory. On admission, she appeared to be emaciated, slightly dehydrated and could not walk without assistance. She had a height of $155 \mathrm{~cm}$ and a weight of $30 \mathrm{~kg}$. The blood pressure was $98 / 58 \mathrm{mmHg}$ and the pulse rate $86 / \mathrm{min}$ and regular. The examinations of chest, heart and abdomen were normal. Neurological examination showed generalized muscular weakness. On the first hospital day, plasma sodium was $131 \mathrm{mEq} / l$ and plasma potassium was $1.9 \mathrm{mEq} / l$. Creatinine clearance was $50-58 \mathrm{~m} / / \mathrm{min}$. Plasma calcium and phosphorus concentrations were normal. Liver and pancreatic functions were normal. Glucose tolerance test was normal. On a regular hospital diet (sodium 200-250 mEq/day) with potassium supplement (potassium $180 \mathrm{mEq}$ ), the patient excreted 3-6 liters urine containing about $320-410 \mathrm{mEq}$ sodium and $175-260 \mathrm{mEq}$ potassium. The urine specific gravity was 1.006-1.008.

Urinalysis was negative for protein or sugar and urine pH ranged from 6.0 to 9.0. Urine culture was negative. Ammonium chloride acidification test showed a decrease in urine below $\mathrm{pH}$ 6.0. Thyroid function, $17 \mathrm{OHCS}$ and $17 \mathrm{KS}$ were normal. Intravenous pyelogram demonstrated a somewhat delayed appearance of dye in both kidneys and slight bilateral dilation of the collecting system. Renal biopsy showed a marked hyperplasia of the juxtaglomerular apparatus.

\section{Materials and Methods}

Sephadex G-75, G-100 and QAE-Sephadex A-50 ( $3.0104 \mathrm{mEq} / \mathrm{g}$ ) were obtained from Pharmacia Fine Chemicals, Uppsala, Sweden. DEAE-cellulose (0.92 $\mathrm{mEq} / \mathrm{g}$ ) were purchased from Brown Chemicals, U.S.A. Carrier Amphorite ( $\mathrm{pH}$ range 3.5 to 5.0) was purchased from LKB Produkter AB, Sweden. AcAME, AGLME, AME, BAME, LME, TAME and TLME were supplied from Peptide Institute Co., I td., Osaka, Japan. PAME and ZAME were kindly supplied from Dr. Kouichi Dobashi, Teikoku Hormone Mfg. Co. Ltd. Angiotensin II (Hypertensin Ciba) was a gift from Chiba Geigy Co. Ltd., Tokyo.

Plasma renin activity and plasma aldosterone conconcentration were measured by radioimmunoassay (CEA-IRE-SORIN, France).

\section{Esterolytic activity}

Esterolytic activities of HUK were measured by the three methods, e.g., fluorometry (Matsuda et al., 1976a), colorimetry (Moriwaki et al., 1971) and spectrophotometry (Schwert \& Takenaka, 1955; Hummel, 1959), using BAME, TAME and other synthetic substances as substrates. All of these three methods were in good agreement. All of esterolytic activities were expressed in terms of esterase unit (E.U.) which is identical in terms of $\mu$ moles substrate hydrolyzed per min.

\section{Vasodilator activity}

This was assayed by the method reported previously (Moriya et al., 1965), by measuring the increase in arterial blood flow in dogs. This activity was expressed in terms of kallikrein units (K.U.).

\section{Purification of urinary kallikrein}

Purification was carried out under the methods and experimental conditions as previously reported (Matsuda et al., 1976b) with a slight modification. Briefly, deionized water was added to the original urine $(12.7 l)$, made up to $120 l$. After adjusting the $\mathrm{pH} 7.0$ to $7.5,40 \mathrm{~g}$ of DEAE-cellulose was added to the solution. After absorption by stirring for $2 \mathrm{hr}$ and then DEAE-cellulose was packed in a column $(3.6 \times 50 \mathrm{~cm})$. Crude extracts were eluted with $0.05 \mathrm{M}$ phosphate buffer, pH 7.5 containing $0.5 \mathrm{M} \mathrm{NaCl}$. This crude extract was purified by the following procedures, e.g., DEAE-cellulose chromatography, Sephadex G-100 gel filtration, QAE-sephadex A-50 chromatography and Sephadex G-75 gel filtration in this order, Final preparation of urinary kallikrein was used for the investigations.

Isoelectric focusing fractionation Isoelectric focusing fractionation was performed 
as reported previously (Matsuda et al., 1976b). Briefly isoelectric focusing was performed with carrier ampholyte (pH 3-5) on LKB8100 equipment. Electrophoresis was carried out at 500 volts and $6-8^{\circ} \mathrm{C}$ for $40 \mathrm{hr}$.

\section{Determination of protein concentration}

Protein concentration was determined spectrophotometrically by measuring the absorbance at 280 $\mathrm{nm}$, using a Hitachi spectrophotometer, model 124 with a cell of $1 \mathrm{~cm}$ light path, and the amount of protein was calculated taking a value for the extinction coefficient of $\mathrm{HUK}, \mathrm{E}_{280}^{1 \%}$ of 14.1 .

\section{Results}

\section{Hospital course (Fig. 1)}

When the patient was put on a regular hospital diet (sodium 200-250 mEq/day) with potassium gluconate $(180 \mathrm{mEq}$ potassium), there was noted a gradual return of serum potassium up to $2.8-3.2 \mathrm{mEq} / \mathrm{l}$ from $1.9 \mathrm{mEq} / l$. Then her muscle strength returned and she was able to be up and about. Subsequently potassium supplements were discontinued. Serum potassium again fell to $1.6 \mathrm{mEq} / l$. At this time urinary kallikrein ranged from 27.3 to 50.1 E.U./day (normal range $8.60 \pm 3.8$ E.U./day) and plasma renin activity $26.04-45.47 \mathrm{ng} / \mathrm{m} / / \mathrm{hr}$ (normal range $1.68 \pm 1.18$ ) and plasma aldosterone $2282.5-2839.7 \mathrm{pg} / \mathrm{ml}$ (normal range $147.1 \pm 81.6 \mathrm{pg} / \mathrm{m} l)$. Then $75 \mathrm{mg}$ of indomethacin was administered. There was noted an increase in serum potassium to $2.8-3.2 \mathrm{mEq} / l$, which was accompanied by a decrease in plasma renin activity to $4.6-8.2 \mathrm{ng} / \mathrm{m} l / \mathrm{hr}$, plasma aldosterone to $380.5-420.7 \mathrm{pg} / \mathrm{m} l$ and urinary kallikrein to 12.6-14.5 E.U./day. Since then she has been treated with $75 \mathrm{mg}$ of indomethacin and $180 \mathrm{mEq}$ of potassium gluconate. Serum potassium gluconate. Serum potassium has ranged between $3.2-3.8 \mathrm{mEq} / l$ and the patient gained weight by about $11 \mathrm{~kg}$ during her hospitalization.

Angiotensin II infusion test (Fig. 2)

The pressor response to angiotensin II was measured at a rate of infusion of $10 \mathrm{ng} / \mathrm{kg} / \mathrm{min}$ of angiotensin II for $60 \mathrm{~min}$, when the patient was receiving potassium supplements alone and also indomethacin together with potassium supplements. Without indomethacin, there was virtually no

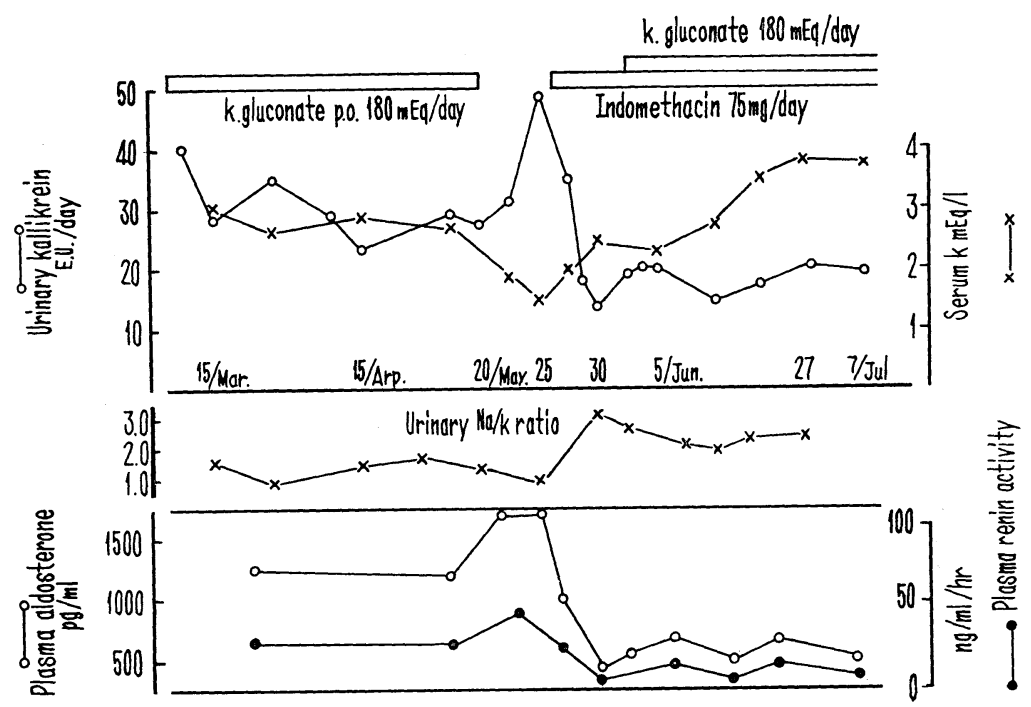

Fig. 1. Effect of $75 \mathrm{mg} /$ day of indomethacin administration on urinary kallikrein, urinary $\mathrm{Na} / \mathrm{K}$ ratio, serum $\mathrm{K}$, plasma renin activity and plasma aldosterone. 


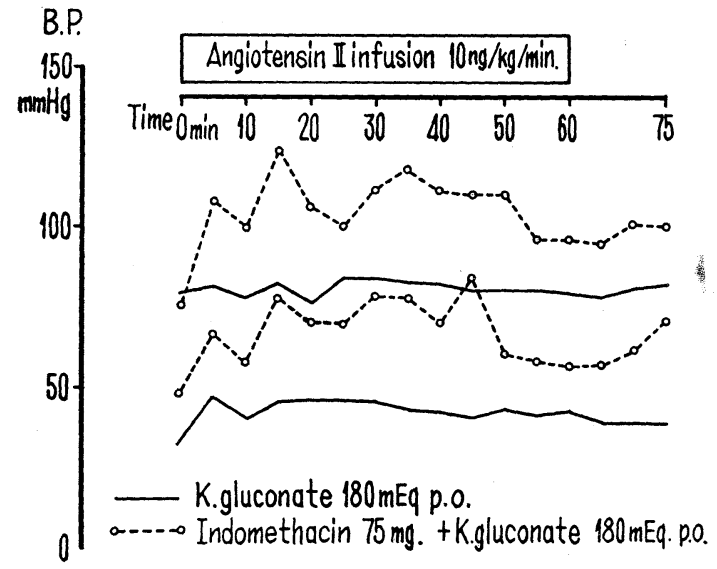

Fig. 2. Effect of indomethacin administration on pressor response to angiotensin II.

response to angiotensin II. However, when indomethacin was given, a marked improvement of the blood pressure response to angiotensin II $(50 \mathrm{mmHg}$ rise in systolic pressure and $30 \mathrm{mmHg}$ in diastolic pressure) was demonstrated.

Purification on urinary kallikrein in the patient with Bartter's syndrome (Table 1)

A summary of the purification procedures and the esterolytic activity of the purified kallikrein were shown in Table 1. From the starting materials, 8090-fold purification was achieved with $16 \%$ activity recovery. The specific activity of the final preparation was 20.1 E.U. per A 280 (esterolytic assay) and $550 \mathrm{KU}$ per A 280 (vasodilator assay).
Estimation of the molecular weight (Fig. 3)

The molecular weight of the components of normal HUK and urinary kallikrein in the patient with Bartter's syndrome was. estimated by gel filtration on a Sephadex G-100 column. The approximate molecular weight of urinary kallikrein in the patient with Bartter's syndrome was $4.2 \times 10^{4}$, which was greater than those of normal HUK (HUK-1 and HUK-2 $2.7 \times 10^{4}$, and HUK-3 $\left.2.9 \times 10^{4}\right)$ as reported previously by Matsuda et al. (1976 b).

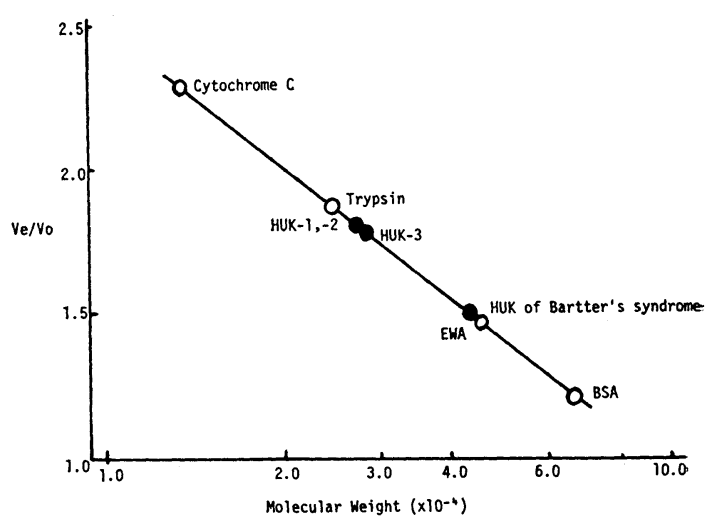

Fig. 3. Estimation of the molecular weight of normal HUK and urinary kallikrein in the patient with Bartter's syndrome. The molecular weights. of the three components of normal HUK and urinary kallikrein from the patient with Bartter's syndrome were estimated by gel filtration on a Sephadex G-100 column, as previously reported by Matsuda et al. (1976). Cytochrome C (M. W. $\left.1.3 \times 10^{4}\right)$, trypsin (M. W. $\left.2.37 \times 10^{4}\right)$, egg white albumin EWA $\left(\right.$ M. W. $\left.4.45 \times 10^{4}\right)$ and bovine serum albumin BSA, (M. W. $6.7 \times 10^{4}$ ) were used as marker protein.

Table 1. Summary of purification of urinary kallikrein in the patient with Bartter's syndrome.

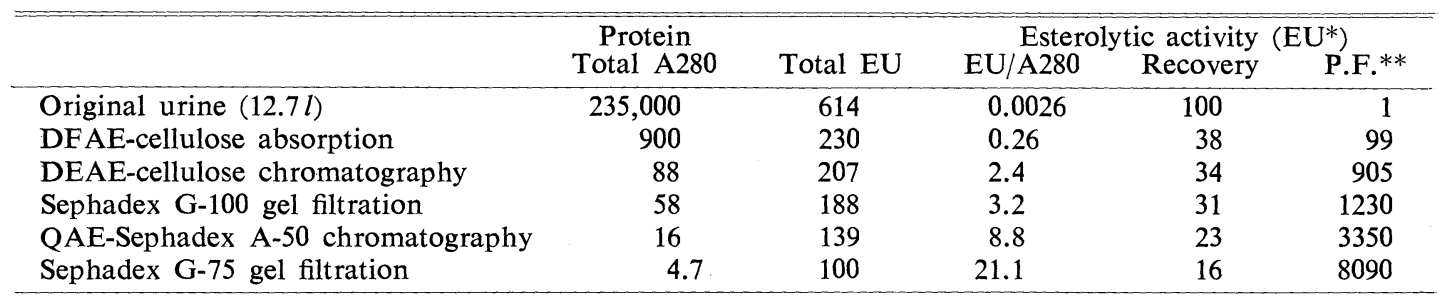

* EU: $1 \mu$ mole TAME hydrolyzed per min at $\mathrm{pH} 8.0$, at $30^{\circ}$.

** P.F.: Purification factor. 
Estimation of $\mathrm{Km}$ values (Table 2)

$\mathrm{Km}$ values towards synthetic N-substituted arginine esters (TAME and BAME) were determined. As demonstrated in Table 2, $\mathrm{Km}$ values of the purified urinary kallikrein in our patient with Bartter's syndrome was not correspondent with any one of those three components of normal HUK.

\section{Isoelectric focusing fractionation (Fig. 4)}

The purified urinary kallikrein in our patient with Bartter's syndrome was applied to an Ampholine column. As shown on

Table 2. Km values of urinary kallikreins in normal subjects and the patient with Bartter's syndrome.

\begin{tabular}{lcc}
\hline \multirow{2}{*}{ urinary kallikrein } & \multicolumn{2}{c}{ Substrate } \\
\cline { 2 - 3 } & TAME & BAME \\
\hline HUK-1 & 750 & 330 \\
HUK-2 & 490 & 190 \\
HUK-3 & 330 & 230 \\
Bartter's syndrome & 410 & 710 \\
\hline
\end{tabular}

$\mathrm{Km} \mu \mathrm{M}$ at $\mathrm{pH}$ 8.0.

$\mathrm{Km}$ values of urinary kallikreins from normal subjects (Matsuda et al., 1976) and the patient with Bartter's syndrome towards TAME and BAME were determined by Lineweaver-Burk plots. Esterolytic activities were assayed spectrophotometrically, measuring the increase in absorbancy at $247 \mathrm{~nm}$ (TAME) and $254 \mathrm{~nm}$ (BAMF). the left side, one component of urinary kallikrein was obtained in our patient, of which the isoelectric point was pI 4.3. On the contrary, as shown on the right side, three components of urinary kallikrein purified from the urine collected on a large scale from normal male persons were separated by isoelectric focusing and were named HUK-1 (Human Urinary Kallikrein 1, pI 3.9), HUK-2 (pI 4.0) and HUK-3 (pI 4.2 , respectively.

Esterolytic activities of urinary kallikreins towards $N$-substituted ariginine and lysine esters (Table 3)

Esterolytic activities of the purified urinary kallikreins obtained from normal subjects and the patients with Bartter's syndrome towards various synthetic arginine and lysine esters were investigated. As demonstrated in Table 3, esterolytic activities of urinary kallikrein in our patients with Bartter's syndrome showed only a slight difference, compared with those of any one of these three types of normal HUK.
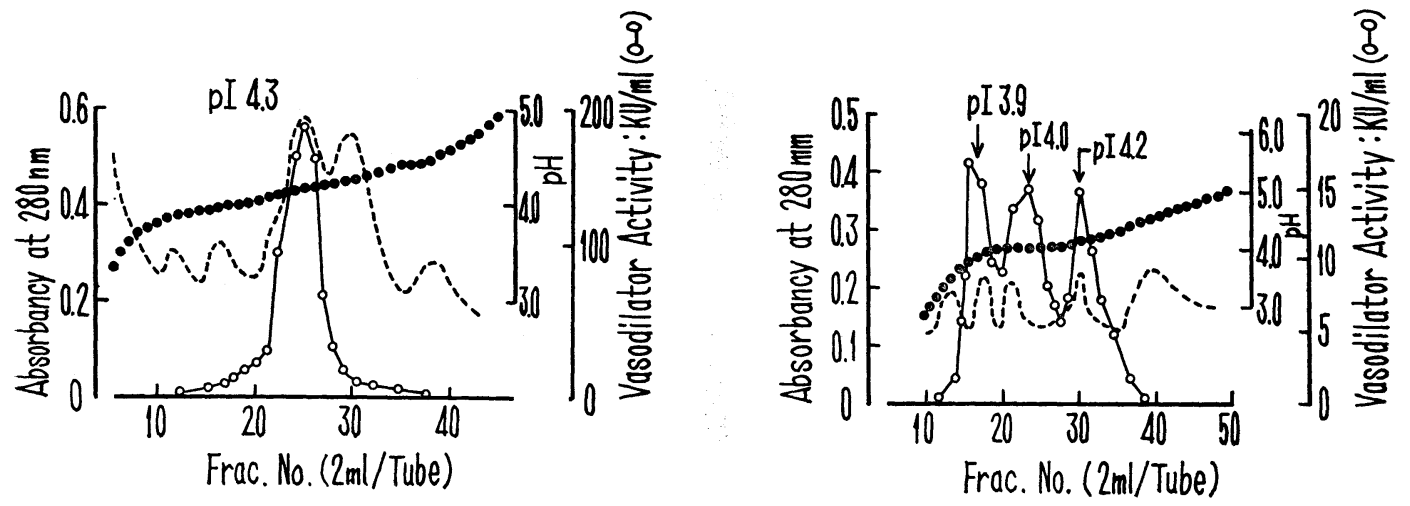

Fig. 4. Isoelectric focusing fractionation of urinary kallikrein in normal subjects and the patient with Bartter's syndrome using an Ampholine system. As shown on the right side, three components of normal HUK were separated by this process and named HUK-1 (pI 3.9), HUK-2 (pI 4.0) and HUK-3 (pI 4.2). As shown on the left side, urinary kallikrein in the patient with Bartter's syndrome had one component (pI 4.3).

- $\mathrm{pH}$ value, $\bigcirc-0$ vasodilator activity using dogs, - - - concentration of protein. 
Table 3. Esterolytic activities of urinary kallikreins in normal subjects and the patient with Bartter's syndrome.

\begin{tabular}{|c|c|c|c|c|c|}
\hline \multirow{2}{*}{ Subtsrate } & \multicolumn{4}{|c|}{ Normal } & \multirow{2}{*}{ Bartter's syndrome } \\
\hline & HUK-1 & HUK-2 & HUK-3 & Mixed & \\
\hline TAME & 100 & 100 & 100 & 100 & 100 \\
\hline PAME & 68 & 71 & 99 & 140 & 115 \\
\hline BAME & 52 & 51 & 51 & 62 & 65 \\
\hline ZAME & 69 & 71 & 61 & 69 & 67 \\
\hline AcAME & 39 & 32 & 27 & 38 & 46 \\
\hline AME & $0 *$ & $0 *$ & $0 *$ & 13 & 18 \\
\hline TLME & 28 & 31 & 30 & 27 & 27 \\
\hline AGLME & 25 & 16 & 15 & 17 & 23 \\
\hline LME & 10 & 15 & 16 & 2 & 1 \\
\hline
\end{tabular}

*: Trace.

Spectrophotometrically measured esterolytic activities of three components of normal HUK, mixed normal HUK and urinary kallikrein of Bartter's syndrome using various $\mathrm{N}$-substituted synthetic arginine and lysine esters were compared with esterolytic activity of these kallikreins using TAME as substrate.

\section{Discussion}

Exceedingly high values of urinary kallikrein and the restoration of pressor response to angiotensin II after the administration of indomethacin in our patient with Bartter's syndrome are in agreement with the previous reports (Lechi et al., 1976; Halushka et al., 1977). Indomethacin, an inhibitor of prostaglandin synthesis, suppressed the renin-angiotensin-aldosterone system, decreased urinary kallikrein in this patient and increased serum potassium concentration. But they were not corrected to normal levels, similar to the report by Gill et al. (1976a). Urinary kallikrein has been reported to be also high in primary aldosteronism in which the renin-angiotensin system is suppressed by the excess of aldosterone production (Margolius et al., 1974).

So in Bartter's syndrome and primary aldosteronism, the stimulation and the suppression of the renin-angiotensin system, though opposite in direction, are associated with an increase in urinary kallikrein excretion and aldosterone production. Moreover, spironolactone, aldosterone anagonist is said to decrease kallikrein excretion (Lechi et al., 1976; Margolius et al., 1974). Thus the evidence described above favours the hypothesis that kallikrein excretion is primarily related to mineralocorticoids such as aldosterone. Then the explanation for the decline of urinary kallikrein excretion by indomethacin therapy in our patient is that indomethacin inhibited a prostaglandin mechanism which participated in the regulation of renin-angiotensin system, leading to an decrease in aldosterone production followed by a decline of urinary kallikrein excretion, though there still remain another possibility that the decreased renal prostanglandins with indomethacin administration alter the activity of the kallikreinkinin system (Halushka et al., 1977).

From the data presented here, it can be mentioned that isoelectric point, molecular weight and $\mathrm{Km}$ value in our patient did not correspond to those observed in any one of the three types of urinary kallikrein reported previously by Moriya et al., suggesting that the character of urinary kallikrein of this patient did qualitatively differ from normals. According to Moriya and his co-workers, the molecular weight of dog renal kallikrein was larger than that of dog urinary kallikrein (Moriwaki et al., 1976). A similar finding was also found in rat (Porcelli et al., 1975). They suggested that the urinary kallikrein might be a partial degradation of renal kallikrein. 
Then it may be speculated that the urinary kallikrein in our patient with Bartter's syndrome was renal kallikrein which was not degraded.

A renal tubular defect has been reported to be at least in part responsible for the pathophysiology of Bartter's syndrome (Tomko et al., 1976; Gill et al., 1977b). As urinary kallikrein is said to be of renal origin (Nustad et al., 1975), so the present findings might be a reflection of renal tubular dysfunction in this patient. Neverthless, it is notable that urinary kallikrein in our patient was still under the influence of renin-angiotensin-aldosterone system or renal prostaglandins system.

Whether this derangement is a primary or secondary phenomenon in Bartter's syndrome is still indeterminate.

\section{References}

Gill, J. R., J. C. Frölich, R. E. Bowden, A. A. Taylor, H. R. Keiser, H. W. Seyberth, J. A. Oates and F. C. Bartter (1976a). Amer. J. Med. 61, 43.
Gill, J. R., F. C. Bartter, A. A. Taylor and N. Radfar (1977b). Clin. Res. 25, 526A.

Halushka, P. V., H. Wohltmann, P. J. Privitera, G. Hurwitz and H. S. Margolius (1977). Ann. Int. Med. 87, 281.

Hummel, B. C. W. (1959). Can. J. Biochem. Physiol. 37, 1393.

Lechi, A., G. Covi, C. Lechi, F. Mantero and L. A. Scuro (1977). J. Clin. Endo. Metab. 43, 1175.

Margolius, H. S., D. Horwitz, R. G. Geller, R. W. Alexander, J. R. Gill, J. J. Pisano and H. R. Keiser (1974). Cir. Res. 35, 820.

Matsuda, Y., H. Moriya, C. Moriwaki, Y. Fujimotoa and M. Matuda (1976a). J. Biochem. 79, 1197.

Matsuda, Y., K. Miyazaki, H. Moriya, Y. Fujimoto, Y. Hojima and C. Moriwaki (1976b). ibid. 80, 671 .

McGiff, J. C. (1977). Ann. Int. Med. 87, 369.

Moriwaki, C., N. Inoue, Y. Hojima and H. Moriya (1971). Yakugaku-Zashi 91, 413. (In Japanese)

Moriwaki, C., K. Miyazaki, Y. Matsuda, H. Moriya, Y. Fujimoto and H. Ueki (1976). J. Biochem. 80, 1277.

Moriya, H., K. Yamazaki, H. Fukushima and C. Moriwaki (1965). ibid. 58, 208.

Nustad, K., K. Vaaje and J. V. Pierce (1975). Brit. J. Pharmacol. 53, 229.

Porcelli, G., G. B. Croxatto, G. Marimi-Bettelo and M. Dilorio (1975). Life Science 16, 788.

Schwert, G. W. and Y. Takenaka (1955). Biochim. Biophys. Acta 16, 570.

Solomon, R. J. and R. S. Brown (1975). Amer. J. Med. 59, 575.

Tomko, D. J., Y. Y. Betty and W. F. Falls (1976). ibid. 61, 111. 